\section{Microscopy Today Innovation Awards}

Congratulations to the winners of the sixth annual Microscopy Today Innovation Awards competition. These awards honor innovative microscopy-related products and methods that appeared in the previous year.

Our team of judges, led by Tom Kelly, looked for innovations that will make new scientific investigations possible. The ten winning innovations were selected on the basis of their importance and usefulness to the microscopy community. In general the entries most likely to win are those that provide better, faster, or entirely new methods of analysis using some type of microscope or microanalytical instrument.

The 2015 Microscopy Today Innovation Award winners are:

Daylight Solutions, Inc. for the Spero ${ }^{\mathrm{TM}}$ Infrared Microscope providing chemical imaging using a tunable laser

E.A. Fischione Instruments, Inc. for the Model 1080 PicoMill ${ }^{\circledR}$ TEM specimen preparation system

Gatan, Inc. for the OneView ${ }^{\mathrm{TM}}$ Camera enabling in situ images at high frame rates

Klocke Nanotechnik GmbH for the Nanoworkbench enabling hand-eye coordination at the nanoscale

National Institute of Standards and Technology for Scanning Ion Microscopy with low-energy Li ions

Nanolive SA for the 3D Cell Explorer enabling 3D movies of unstained live cells

Nanonics Imaging, Ltd. for the CryoView $\mathrm{MP}^{\mathrm{TM}}$ enabling multi-probe measurements at 10 Kelvin

Aydogan Ozcan of UCLA for Lens-Free Computational Microscopy enabling giga-pixel 3D imaging

Phenom-World BV for the Delphi combining fluorescence microscopy with electron microscopy

Carl Zeiss Microscopy GmbH for the MultiSEM 505 providing high-throughput imaging with 61 electron beams

Descriptions of the above innovations are given in an article within this issue. This article also lists the developers of these instruments and methods.

Details of the nomination process for the next competition will be posted on the Microscopy Today website (www.microscopy-today.com) by January 1, 2016. Nomination applications will be accepted through March 21, 2016.

Charles Lyman

Editor-in-Chief

Publication Objective: to provide information of interest to microscopists.

Microscopy Today is a controlled-circulation trade magazine owned by the Microscopy Society of America that is published six times a year in the odd months. Editorial coverage spans all microscopy techniques including light microscopy, scanning probe microscopy, electron microscopy, ion-beam techniques, and the wide range of microanalytical methods. Readers and authors come from both the life sciences and the physical sciences. The typical length of an article is about 2,000 words plus figures and tables; feature articles are longer. Interested authors should consult "Instructions for Contributors" on the Microscopy Today website: www.microscopy-today.com.

\section{ISSN 1551-9295}

\section{Disclaimer}

The Microscopy Society of America and the editors cannot be held responsible for opinions, errors, or for any consequences arising from the use of information contained in Microscopy Today. The appearance of advertising in Microscopy Today does not constitute an endorsement or approval by the Microscopy Society of America of any claims or information found in the advertisements. By submitting a manuscript to Microscopy Today, the author warrants that the article is original or that the author has written permission to use copyrighted material published elsewhere. While the contents of this magazine are believed to be accurate at press time, neither the Microscopy Society of America, the editors, nor the authors can accept legal responsibility for errors or omissions.

\section{Editorial Staff}

Charles E. Lyman, Editor-in-Chief charles.lyman@lehigh.edu (610) 758-4249

Gennifer Levey, Production Manager glevey@meridianartpro.com (212) 780-0315

Ron Anderson, Executive Editor microscopytoday@tampabay.rr.com Phil Oshel, Technical Editor oshellpe@cmich.edu

Stephen Carmichael, Columnist carmichael.stephen@mayo.edu Michael Davidson, Pioneers Editor davidson@magnet.fsu.edu

Steven Barlow, Education Editor sbarlow@mail.sdsu.edu

Thomas E. Phillips, Consulting Editor phillipst@missouri.edu

E. Ann Ellis, Microscopy 101 Editor eann.ellis@suddenlink.net

Paul Webster, Calendar Editor pwebster@usc.edu John Shields, Humor Editor jpshield@uga.edu

Thomas Kelly, Chief Awards Judge Thomas.kelly@ametek.com

Advertising Sales

M.J. Mrvica Associates, Inc.

2 West Taunton Avenue, Berlin, NJ 08009 mjmrvica@mrvica.com

(856) 768-9360

Kelly Miller, Account Manager

kmiller@mrvica.com

Magazine website:

http://www.microscopy-today.com

Free subscriptions are available

Publisher

Cambridge University Press

32 Avenue of the Americas

New York, NY 10013-2473

(212) $337-5000$

Circulation: 18,000

Editorial Board

Arlan Benscoter, Lehigh University John Bozzola, Southern Illinois University Peter Crozier, Arizona State University Vinayak Dravid, Northwestern University David Grubb, Cornell University

Bryan Huey, University of Connecticut John Mackenzie, North Carolina State Univ. Paul Maddox, University of Montreal Ania Majewska, U. Rochester Med School Greg Meeker, U.S. Geological Survey Joseph Michael, Sandia National Labs Caroline Miller, Indiana University Brian M. Patterson, Los Alamos National Lab Robert Price, University of South Carolina John Reffner, John Jay College, SUNY Ian Robertson, University of Wisconsin Phillip Russell, Appalachian State University Glenn Shipley, Citizen Microscopist Robert Simmons, Georgia State University Paul Voyles, University of Wisconsin Simon Watkins, University of Pittsburgh Cynthia Zeissler, Nat. Inst. of Sci. and Tech. (NIST) 